\title{
TURISMO RELIGIOSO EN URUGUAY. EL CASO DE LA FESTIVIDAD DE SAN CONO
}

\author{
Pedro Ernesto Moreira Gregori* \\ Enrique Coraza de los Santos ${ }^{* *}$ \\ Pablo de la Rosa ${ }^{* * *}$ \\ Bruno Giannattasio ${ }^{* * *}$
}

\section{RESUMEN}

Si bien el Uruguay es desde sus orígenes un Estado laico, la mayoría de los uruguayos profesan algún tipo de religión o participan de alguna manifestación religiosa. En el marco de este fenómeno presentamos un estudio centrado en las celebraciones católicas populares. A través de metodologías cualitativas, analizamos un fenómeno donde se combinan la movilidad humana y el turismo religioso con la fe y la devoción. El presente caso de estudio se localiza en la ciudad de Florida, Uruguay, donde se encuentra la capilla de San Cono. Se trata de la imagen de un santo nacido en Teggiano (Italia): imagen introducida por migrantes italianos a fines del siglo XIX, la cual despierta una gran devoción, estando asociada a la suerte y el dinero, atribuyéndosele milagros y sanaciones.

Palabras Clave: turismo religioso, Uruguay, san Cono.

\author{
RELIGIOUS TOURISM IN URUGUAY. \\ THE CASE OF SAN CONO FESTIVITY
}

\section{Abstract}

Although Uruguay is from its origins a secular state, most Uruguayans profess some kind of religion or participate in some religious demonstration. Within the framework of this phenomenon is that we present a study focused on popular catholic celebrations. Through qualitative methodologies, we analyze a phenomenon where mobility and religious tourism are combined, with feelings, faith and devotion. This case study is located in the city of Florida, Uruguay where the Chapel of San Cone is located. It is an Italian Saint born in the city of Teggiano: image introduced by Italian migrants in the late nineteenth century, it wakes up great devotion, being associated with luck and money, attributing miracles and healings to it.

KeYwords: religious tourism, Uruguay, San Cono. 


\section{INTRODUCCIÓN}

Aunque Uruguay histórica, y hasta políticamente, ha sido considerado como un país laico por su tradición liberal, e incluso, con una fuerte presencia de la masonería, es cierto que en la realidad una importante porción de la población profesa o acompaña diferentes manifestaciones y formas de la religiosidad, desde las de raíz católica o cristiana, hasta las afrobrasileñas. La devoción a santos, divinidades e imágenes recuerdan ancestrales prácticas algo lejanas a la institucionalidad y oficialidad de «La Religión». Durante el fenómeno de secularización se fue dando en la relación Iglesia-Estado un proceso creciente de reducción de lo religioso al ámbito de lo privado, alejándose de lo público. La Constitución uruguaya de 1917 promulgó la separación total de la Iglesia y el Estado, perdiendo esta su relevancia y peso predominante, articulándose desde el Estado un imaginario colectivo prescindente de la esfera religiosa. Desde la época colonial, la implantación de la Iglesia en el Uruguay fue tardía, con pocos medios económicos y dinamismo, y a su vez muy dependiente de la autoridad eclesiástica de la diócesis de Buenos Aires. Posteriormente, el Estado autoproclamó y plasmó su hegemonía sobre la Iglesia durante un largo proceso, en el cual, esta última reconoció su derrota, denominándola como parte del proceso de «descristianización» de la sociedad (Corbo, 2011). De todas formas, y como señala Da Costa (2003), si bien el Uruguay es un país desde su origen laico, la religiosidad popular tiene una fuerte presencia en la ciudadanía. Tal afirmación surge, entre otras cosas, de la encuesta que el autor presenta sobre hábitos religiosos de los montevideanos: $12 \%$ asiste a cultos a la Virgen María (principalmente Virgen de Lourdes y Virgen de Verdún), 14\% asiste al culto de 3 santos (san Pancracio, san Cono y san Cayetano), 6,5\% asiste al culto de Iemanjá (religiosidad afrobrasileña), y $15 \%$ participa en otro tipo de diversos cultos.

En este texto presentamos un estudio centrado en las celebraciones populares, en un fenómeno colectivo, de masas, constituido por las procesiones de origen católico. Analizamos la procesión como un viaje físico y espiritual, un fenómeno donde se combinan la movilidad, el turismo religioso y el patrimonio material e inmaterial, tangible e intangible. En él, atendemos a elementos como el sentimiento de fe, la devoción a un santo de origen y seguimiento popular, y a los milagros que se le atribuyen y agradecen a través de ofrendas y manifestaciones diversas. Lo señalado lo ha convertido en un fenómeno turístico y de masas que se sucede en el espacio entre «lo sagrado» y «lo profano» situándose, los visitantes, en un amplio espectro entre los "peregrinos puros» $\mathrm{y}$ "los turistas puros», y como expresión diversa del denominado «turismo religioso» (imagen 1).

* Departamento de Psicología, Sociología y Trabajo Social e Instituto Universitario de Turismo y Desarrollo Económico Sostenible (TIDES). Universidad de Las Palmas de Gran Canaria, España (ULPGC).

** Departamento de Sociedad y Cultura. El Colegio de la Frontera Sur, México (ECOSUR).

*** Facultad de Ciencias Sociales (FCS). Universidad de la República, Uruguay (UDELAR). 


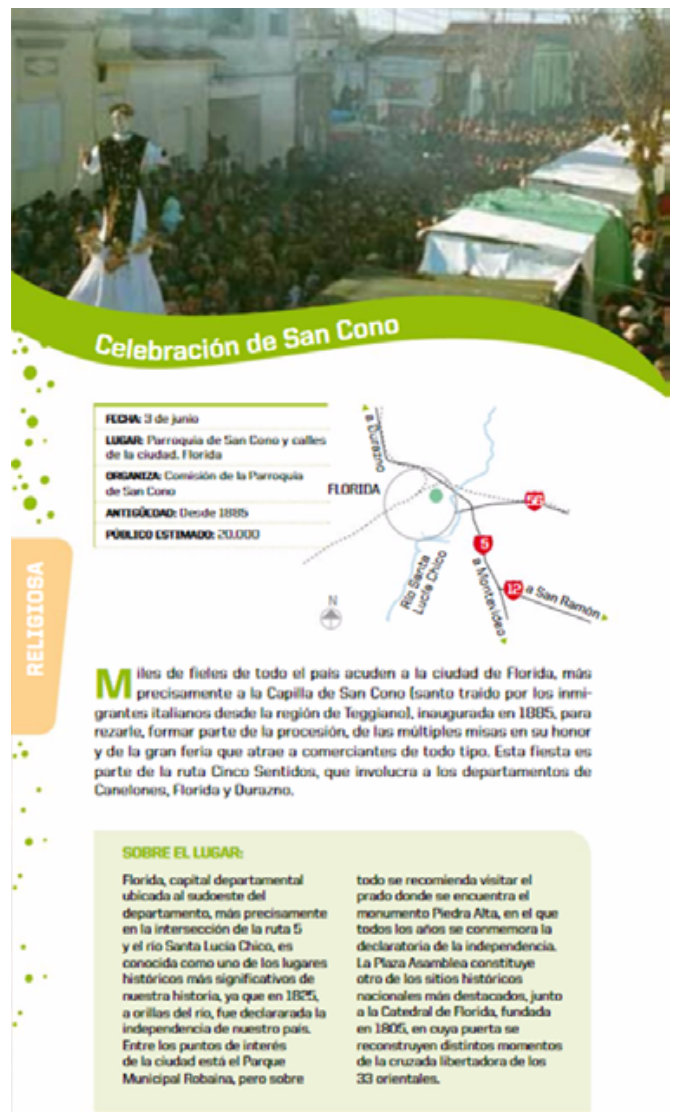

Imagen 1: promoción turística de la "Celebración de San Cono».

Fuente: Ministerio de Educación y Cultura y Ministerio de Turismo de Uruguay (2017).

Nos acercamos de una forma analítica a la procesión a san Cono (de aquí en adelante: SC), un santo italiano nacido en la ciudad de Teggiano (Salerno-Italia) en el siglo XII ubicado en una capilla que se localiza en un barrio de la ciudad de Florida (capital del departamento del mismo nombre en Uruguay) denominado «el barrio de los italianos». Además de Teggiano y el Valle de Diano, de donde es originario, el otro lugar en el mundo donde tiene gran cantidad de devotos es en Uruguay, aunque también se desarrolla el culto en la Provincia de Buenos Aires, en Nueva York y en otras regiones de Italia, pero con menos repercusión y presencia de personas. En Uruguay, ha alcanzado una dimensión nacional, e incluso internacional con presencia de devotos de Argentina y Brasil para su fiesta el 3 de junio. La imagen fue introducida por migrantes italianos a fines del siglo XIX como resultado de una promesa para que les asegurara llegar sanos y salvos a su destino, amén de ser parte de sus tradiciones histórico-culturales locales. Su imagen y su "poder» está asociado a la suerte, el dinero, los juegos de azar, atribuyéndosele milagros y 
sanaciones, motivo por el cual a lo largo de más de cien años se han ido acumulando diversos tipos de objetos en forma de ofrendas. Durante mucho tiempo, las mismas estaban ubicadas en una sala contigua a la capilla pero, hace una década, se constituyó un espacio como museo.

\section{METODOLOGÍA}

Con el objetivo de conocer y comprender las principales características de la «festividad de San Cono» en Florida, Uruguay, presentamos a través de la metodología cualitativa este artículo. Un estudio de caso basado en las técnicas cualitativas de investigación social de: 1) revisión bibliográfica y documental y 2) observación participante, centrándonos en los principales aspectos concluyentes de los registros tomados durante los dos trabajos de campo etnográficos realizados durante las procesiones de junio de 2017 y 2019 (fotografías de diversos elementos contextuales y situacionales, así como grabaciones de entrevistas a visitantes y residentes).

Cabe destacar, por otra parte, que la faceta meramente turística de la festividad ha sido desde el punto de vista metodológico una más de las diversas facetas analizadas, no una faceta exclusiva ni excluyente en el análisis de este complejo, histórico, popular, tradicional y multicausal fenómeno.

En el que, por otra parte, confluye la complejidad de un análisis transversal en el marco de dos grandes dimensiones de universos independientes y con lógicas propias: «el turismo» $\mathrm{y}$ «la religión».

\section{EL TURISMO RELIGIOSO}

Tal y como afirma Collins-Kreiner (2010), la procesión es una de las formas más antiguas y básicas de movilidad de las poblaciones. Las mismas se podrían definir como viajes con fines espirituales e introspectivos, resultantes de causas y motivaciones propias, en relación con un lugar sagrado (Barber, 1993). En las últimas décadas, se estaría dando un cambio hacia un tipo de procesión más asociada al turismo de masas en sí mismo, a lo secular, al disfrute del ocio y del tiempo libre, que a los tradicionales viajes espirituales y de recogimiento religioso. Con el auge de los movimientos turísticos, las visitas a sitios religiosos o espirituales está experimentando un considerable resurgimiento mundial, ya que los tradicionales santuarios actúan aún como imanes para los viajeros con motivaciones religiosas (Digance, 2003). De todas formas, hay una distinción entre los centros de peregrinaje más formales e institucionales (Vaticano, Lourdes, Fátima, La Meca, Belén, Jerusalén, Santiago de Compostela, Taj Mahal, entre otros) y los viajes relacionados con la religiosidad popular y seculares, como nuestro caso de estudio sobre SC en Uruguay. Con claras características relacionadas con las romerías, fiestas y ferias de pueblo, de mezcla entre "lo profano" y «lo sagrado", directa e indirectamente censurado, observado y hasta, en muchas ocasiones, en conflicto con la institucionalidad religiosa. Con el turismo de masas y el consumo turístico, se estaría desdibujando 
el límite entre "peregrino" y «turista», a su vez, los productos y paquetes ofertados de «turismo religioso» satisfacen cada vez más a una creciente demanda, siendo los límites entre turismo y procesión poco claros y difusos. En este aspecto, y como se puede observar en la tabla 1, Cánoves (2006), citando a Smith (1992), analiza la relación entre peregrinaje y turismo como un espectro entre dos extremos de una amplia gama de combinaciones entre «lo sagrado» y «lo secular»: o sea, una escala entre dos extremos puros y tipos ideales entre los que transcurren el resto de matices, abarcando las múltiples motivaciones de viaje a los centros religiosos. En este sentido, la clasificación intermedia entre el "peregrino puro» y el «turista puro» sería la del «turista religioso».

\begin{tabular}{|c|c|c|c|c|c|}
\hline \multirow[b]{2}{*}{ Individuo } & \multicolumn{2}{|c|}{ Peregrinaje } & \multirow{2}{*}{$\begin{array}{c}\text { TURISMO RELIGIOSO } \\
\text { Turista religioso }\end{array}$} & \multicolumn{2}{|c|}{ Turismo } \\
\hline & $\begin{array}{l}\text { Peregrino } \\
\text { puro }\end{array}$ & $\begin{array}{c}\text { Más peregrino } \\
\text { que turista }\end{array}$ & & $\begin{array}{l}\text { Más turista } \\
\text { que peregrino }\end{array}$ & Turista puro \\
\hline $\begin{array}{l}\text { Motivación } \\
\text { principal de } \\
\text { la visita }\end{array}$ & & grado & $\begin{array}{l}\text { Sagrado secular. } \\
\text { Turismo cultural de } \\
\text { patrimonio religioso }\end{array}$ & & \\
\hline
\end{tabular}

Fuente: elaboración propia basado en Cánoves (2006) citando a Smith (1992).

Lo que está claro es que no todos los sitios sagrados que atraen a peregrinos atraen necesariamente a turistas culturales: por cada sitio sagrado destacado en la ruta turística, hay otros miles que no aparecen en estos circuitos (Nyaupane et al., 2015). Aunque también debería señalarse que, en muchos casos, hay sitios religiosos con acceso restringido solo a los fieles (p. ej., La Meca). Por otra parte, las experiencias de las personas en los lugares sagrados son diferentes en función de su afiliación religiosa o la falta de esta (Griffiths, 2011; Shackley, 2001). Para los turistas religiosos, tales visitas pueden provocar sentimientos de fervor religioso, mientras que, para los turistas no religiosos, sensaciones de asombro e inspiración cultural, diferenciándose, las motivaciones de viaje según sean peregrinos (puros) o turistas (puros). También, y motivados principalmente por intereses culturales y por la curiosidad, es común la visita a determinados lugares sagrados, diferentes a los de la confesión religiosa del propio turista. Sobre las motivaciones religiosas del viaje, Terzidou et al. (2018) inciden en cómo las representaciones sobre lo religioso y las experiencias espirituales vividas personalmente potencian la visita a lugares religiosos e influyen en las motivaciones para visitarlos, otorgando, en la decisión del viaje, un valor central a los factores motivacionales "push» (de empuje y más relacionados con la demanda), sin olvidar el peso de los factores motivacionales "pull» (de atracción y más relacionados con la oferta). De la Torre et al. (2016), en su artículo sobre los factores que determinan el crecimiento del turismo en destinos religiosos, señalan un aumento de las motivaciones no religiosas del viaje, motivaciones complejas y multidimensionales (culturales, sociológicas y espirituales) relacionando, directamente, la motivación religiosa con el nivel de devoción y destacando la importancia de la coordinación entre las autoridades laicas y religiosas para el desarrollo de los 
destinos religiosos. Además del crucial aporte de empresarios, autoridades locales y autonómicas en la puesta en marcha de políticas turísticas y culturales que potencien y maximicen los destinos religiosos, estos se traducen en un beneficio, no solo para los visitantes, sino también para el propio sitio religioso, como promoción de sus valores culturales y como forma de financiamiento y mantenimiento del patrimonio cultural que lo integra.

Asimismo, destacamos la revisión que sobre la literatura en inglés y en español del vínculo turismo-procesión realizan Torres et al. (2017), quienes señalan que, en la producción en inglés, se ve una convergencia entre el turismo y la procesión en el sentido de que el turismo podría tener una connotación sagrada, mientras que la procesión, una connotación recreativa. Así, surge el «turismo religioso» como el término referente y confluyente entre «el turismo» y «la procesión». Mientras que, en los textos en español, se ve cierto consenso en considerar al «turismo religioso" como una modalidad más de turismo alternativo en sí mismo y relacionado con la comercialización de la cultura. De esta forma, el peregrino se inscribe dentro de un tipo de turista particular en la amplia tipología en la que el mismo se inscribe (ocio, cultura, comercial, sanitario y un largo etcétera). Al mismo tiempo, la consideración de lo religioso pasa a ser un producto más de la oferta turística en el marco de la diversificación de la oferta turística local.

Entendemos que por su naturaleza intrínseca y prácticas cotidianas, el turismo religioso y las expresiones de religiosidad popular conllevan el concepto de "patrimonio inmaterial», definido por la UNESCO en la Convención para la Salvaguardia del Patrimonio Cultural Inmaterial (UNESCO, 2003) como

... los usos, representaciones, expresiones, conocimientos y técnicas (junto con los instrumentos, objetos, artefactos y espacios culturales que les son inherentes) que las comunidades, los grupos y en algunos casos los individuos reconozcan como parte integrante de su patrimonio cultural. Este patrimonio cultural inmaterial, que se transmite de generación en generación, es recreado constantemente por las comunidades y grupos en función de su entorno, su interacción con la naturaleza y su historia, infundiéndoles un sentimiento de identidad y continuidad y contribuyendo así a promover el respeto de la diversidad cultural y la creatividad humana. Y se manifiesta en particular en: a) tradiciones y expresiones orales, incluido el idioma como vehículo del patrimonio cultural inmaterial; b) artes del espectáculo; c) usos sociales, rituales y actos festivos; d) conocimientos y usos relacionados con la naturaleza y el universo; e) técnicas artesanales tradicionales.

\section{SAN CONO EN URUGUAY: SUS ORÍGENES, ANTECEDENTES Y PRINCIPALES CARACTERÍSTICAS}

Desde comienzos del siglo xx se verificó en Uruguay un fuerte proceso de secularización que configuró un sistema institucional de valores, convicciones, símbolos y relatos cívicos que conformarían la identidad nacional de los uruguayos, en un modelo de ciudadanía "hiperintegradora» donde en un proceso de modernización 
un estatismo casi cultural comenzó poco a poco a monopolizar la idea de lo público y el concepto expandido de la ciudadanía quedó atrapado en forma gradual en una suerte de superego ciudadano celoso y absorbente, que transfería la dimensión de lo religioso institucional al terreno de lo privado (Caetano, 2006: 129).

Respecto de la inmigración italiana como influencia del catolicismo popular uruguayo, Sánchez y Geymonat (1996) sugieren que en el contexto de esa inmigración, y su relación con la religiosidad institucional, se dieron factores clave en el proceso de secularización uruguayo, donde a su vez

el traslado de devociones populares italianas al medio criollo llevó a que estas se cargaran de nuevos significados [...] (no pudiendo escapar a un) complejo fenómeno de fusión social que se dio a todos los niveles entre los migrantes italianos y la sociedad criolla (175).

Dejando, la manera italiana, su impronta en estas devociones donde, en algunos casos, el elemento religioso pasa a segundo plano, y las fiestas de los santos llegan a ser, sobre todo, fiestas populares, caracterizadas por las ferias, plazas de mercado, música, con espectáculos ruidosos, presencia masiva, elementos lúdicos como el juego, surgiendo como una fuerte función identitaria respecto a la patria de origen y las tradiciones o de reencuentro con compatriotas como un factor aglutinador de colectividades.

Fue el 3 de junio de 1888 el día que se realizó la primera procesión con una imagen de SC en Uruguay llevada a Florida desde Argentina e instalada provisionalmente en una capilla construida con ese propósito. En 1892, es incorporada una nueva imagen, esta vez traída desde su lugar de origen (Teggiano, Italia). La separación de la Iglesia y el Estado por la Constitución de 1917 dejó a la vista los primeros conflictos entre la Iglesia católica y los administradores de la imagen de SC, sobre todo respecto al control de la capilla y la fiesta. En la carta magna se le reconocía a la Iglesia católica el dominio sobre todos los templos que hayan sido, total o parcialmente, construidos con fondos del erario nacional, con algunas excepciones. Esto fue fuente de un extenso litigio en donde, al final, se le reconoció a la asociación civil que hasta el día de hoy gestiona la capilla la posesión de los bienes. Innumerables conflictos se sucedieron hasta que, alrededor del año 1950, se judicializa el conflicto, resultando que la posesión de la capilla fue reconocida a la asociación desestimando la demanda de la Iglesia católica ${ }^{1}$. Igualmente, la Iglesia ha seguido con la participación en la fiesta, no exenta de momentos de tensión y conflicto, pues no puede desconocer la presencia de tal cantidad de peregrinos como una manifestación de su fe.

El culto a SC desarrollado en la localidad de Florida está rodeado de diferentes elementos que lo convierten en un caso de estudio por demás interesante, en el

${ }^{1}$ Para una detallada y pormenorizada reconstrucción histórica de este conflicto, desde fines del siglo xIx hasta fines del xx, ver Coraza, 2006. 
cual es necesario trabajar en forma permanente las escalas entre lo micro y lo macro para entender el proceso histórico, su permanencia y continuidad por más de cien años. Por un lado, es comprender cómo la llegada de colectivos migrantes irrumpe en el siglo XIX en la dinámica de un país aún fundamentalmente rural en lo económico y social, dominado por relaciones políticas tensas entre un interior dominado por caudillos conservadores y una capital de corte urbano y liberal, hasta generar un espacio propio y diferenciado si lo reconocemos desde el presente (Barrán, 1982 y Barrán y Nahúm, 1990). Esta transformación en la cotidianeidad y estructuras de una localidad menor del interior uruguayo se produce desde la instalación de una «cultura inmigrante» que reviste una larga historicidad de conflictos, acomodaciones y modificaciones que, aun siendo parte de una larga temporalidad, se mantiene hasta hoy en su memoria colectiva e histórica y se puede observar manifestada en una expresión de religiosidad popular como la «Fiesta de SC». Es decir, aquello que a primera vista puede considerarse como propio del ámbito de lo religioso, en realidad condensa una serie de elementos, materiales y simbólicos que son manifestaciones del poder (Foucault, 1979 y 1981) en todos los ámbitos de la vida social, económica, cultural y política de la ciudad (Barrán, 1994).

La presencia de esta expresión cultural se constituye en elementos de una identidad primaria y simbólica, y de la estructuración de una serie de redes sociales (Bjerg, 1995) que, en algunos casos, comportaron estrategias matrimoniales de tipo endogámico, algo presente en muchas culturas migrantes, o incluso como una estrategia política y económica de concentración del poder, la riqueza o los elementos considerados «la esencia» de una identidad cultural. Esta comunidad italiana de referencia, una vez instalada en la localidad, revivió y construyó una serie de elementos materiales y simbólicos de carácter eminentemente étnico de su cultura de origen, donde se insertó una imagen y un culto a la misma. La mayoría, paulatinamente se fueron integrando a la sociedad y cultura local a través de un proceso de tensión permanente entre asimilación y conflicto, conservando en muchos casos elementos de reconocimiento y de identidad, tanto del grupo étnico de pertenencia (los italianos) como gradualmente de la sociedad local.

En este largo proceso, los elementos culturales étnicos entraron en competencia con elementos de identidad local, o comenzaron a competir por el control cultural $^{2}$ con instituciones de dominio y monopolio de ciertos espacios, no solo religiosos, sino también sociales y políticos, incluso hasta económicos (sobre todo por la relación del santo con la suerte y el dinero). Esta situación llevó a generar entre los grupos sociales una relación dialéctica por el control cultural entre un «nuestro» y un «de los otros», como categorías con connotación social. De esta forma, se conformó una identidad social diferenciada a partir de la identificación de ciertos

2 Aplicamos el concepto de control cultural en el sentido que le asigna Bonfil Batalla (Bonfil Batalla, 1987) como la capacidad social de decisión sobre ciertos elementos culturales; evidenciado no solo en la capacidad de uso, sino también (y más importante aún) en la capacidad de producción y reproducción. 
individuos como pertenecientes a un mismo y exclusivo grupo, reivindicando la existencia de una cultura propia.

En la medida en que el culto a la imagen de SC se sentía parte del catolicismo y permanecía reducido a un ámbito barrial y étnico, no existía, en realidad, una invasión de los espacios tradicionales de acción de los poderes institucionales locales. La comunidad nacida bajo una imagen con carácter simbólico y mítico pasó de una primera y efímera etapa de rechazo a una segunda etapa de reconocimiento y aceptación. Si bien no podemos hablar de una acción uniforme de la comunidad, sí existe una conceptualización unánime, una conciencia social generada por una experiencia que se impone e imprime en el pensamiento. Esta segunda etapa le permitió, a la comunidad nucleada alrededor de la imagen del santo, reconocer el acceso a ciertos niveles de la sociedad local a los que no podría haber ingresado por su sola presencia o acción: la convocatoria, el reconocimiento y el prestigio. Estos elementos devenían de la posesión y control de un objeto: la imagen de SC, por lo tanto, su mantenimiento, cuidado y exhibición eran necesarios para mantenerlos. La capilla de SC fue percibida, no solo como espacio simbólico (Valera, 1996), sino como espacio de poder por las diferentes instituciones locales (incluida la propia comisión de la capilla de SC).

La Iglesia, como institución que monopoliza el control de las creencias de raíz católica, también es capaz de percibir este proceso y de reconocer sus alcances, no solo espirituales, sino también materiales. En la medida en que pierde la protección y legitimidad del Estado por el proceso de separación de Iglesia-Estado en la Constitución de 1917, intenta concentrar todos los espacios, entrando en conflicto con aquellos que han quedado fuera por distintos motivos, como en este, por estar fuertemente controlado, administrado y defendido por la colectividad italiana; de ello dan prueba no solo el conflicto en la ciudad de Florida, sino otros casos en Uruguay y en otros de Latinoamérica. En este caso, la Iglesia se enfrenta a una corporación con fuertes lazos de unión comunitaria, con una profunda percepción de su identidad étnica unida a un fuerte sentido de propiedad y control. Este enfrentamiento se reduce, en su esencia, en una disputa por ese espacio de poder intentando mostrar sus fuerzas a través de la legitimidad del reconocimiento colectivo. De acuerdo al modelo planteado por Natalie Davis (1973), el conflicto aparece como una extensión del ritual religioso percibiéndose cómo, en la mayoría de los casos, la violencia y el enfrentamiento se originan en los momentos de culto a partir de un repertorio de acciones. Estas acciones se identifican con los grupos que las generan, mientras el catolicismo oficial se refugia en el apego a la ortodoxia y la liturgia, la comisión de SC responde con actos que pueden ser considerados de justicia popular, como la recurrencia a la convocatoria masiva y a profundizar en el carácter festivo como forma de legitimidad. La violencia en sí llega a dotarse de legitimidad ritual al crear una legitimidad religiosa junto a la evidencia de la lucha por un poder terrenal, al transformar la naturaleza y el significado de los símbolos. La imagen de SC deja de ser, para las fuerzas en pugna, la representación de un ser mítico con un carácter potente para transformarse en un objeto de disputa, incluso visible en otros elementos materiales, como la posesión de la llave de la capilla o todo lo relacionado con la gestión de esta en sí. 
El conflicto adquiere mayor importancia para la comunidad especialmente en su segunda etapa, por la duración y alcance, así como por la necesidad de redefinición que va a generar en la comunidad. La violencia ${ }^{3}$ lleva a una fragmentación del consenso comunitario a nivel general ${ }^{4}$ a través de una lucha por el poder, en la que cada grupo va a tratar de establecer nuevas fronteras comunitarias. Pueden observarse en el conflicto dos alcances diferentes: uno a corto plazo, determinado por la lucha real por el poder y el control de lo sagrado, pero existe otro, a largo plazo, que muestra cómo ambos grupos llegan a aceptar una nueva concepción de la diversidad y de las tensiones posibles dentro de la comunidad urbana. La dimensión política también está inserta, quedando muy clara a través de la prensa (que responde a intereses políticos), a partir del hecho de que los enfrentados se proyectan en agrupaciones políticas o se identificaban con ellas, o simplemente por el uso de la crítica como forma de desacreditación pública con fines políticos. En definitiva, lo que se observa es cómo un grupo de la comunidad crea, reproduce y mantiene actitudes diversas frente, o en relación con, los sistemas simbólicos, apropiándose de ellos, manteniendo el control, incluso a través de la lucha por el poder de producción y reproducción de esos sistemas simbólicos.

Respecto al nivel de integración (Cohen, 1981) de la comunidad que administra a SC, observamos cómo esta no llega a ser plena y, por tanto, sería más adecuado hablar de inserción (Torres, 2011), carácter que va a mantener, incluso desde el punto de vista legal, hasta hoy a través de los mecanismos de sucesión y reproducción del modelo de control cultural. Si bien pueden reconocerse niveles de inserción desde el punto de vista social o económico, tengamos en cuenta que el carácter de inserción de esa comunidad representa un elemento primordial en su identidad primaria. Respecto a la fiesta de SC, reconocemos la existencia de una percepción, por parte de la sociedad, de pertenencia como manifestación popular parte de la cultura local y nacional; sin embargo, su papel es básicamente de participante, ya que no existen mecanismos de control o cambio fuera de la comisión administradora de la capilla del santo. De todas formas, en la presencia de lo colectivo puede verse cierta influencia de determinación sobre algunas características del culto, pero no llegan a un nivel de decisión. La administración municipal se integra en este proceso a partir del crecimiento de las Fiestas a SC, especialmente producto de las repercusiones del conflicto con la Iglesia a partir de 1946, cuando ve allí un punto de atracción que permite proyectar la localidad fuera de sus fronteras locales. Esa proyección implica desarrollo para los diferentes sectores de la economía local, a la vez que fuente de ingresos por distintos medios. Sin embargo, no percibimos en este nivel un conflicto, como no existe un involucramiento de la administración muni-

${ }^{3}$ Entendiendo la violencia tanto en sus manifestaciones materiales evidenciada en ciertos enfrentamientos, pero también simbólica a través de expresiones de poder, discriminación, exclusión o resistencia, todo ello traducido en una tensión que provoca en la sociedad local de Florida la división entre individuos o grupos que dan la razón a un lado u otro del conflicto.

${ }_{4}$ Comunidad concebida como un grupo social que ha adquirido cierto nivel de consenso colectivo según lo aplica Thompson (Thompson, 1981: 144-145). 
cipal en el conflicto generado, ni una intermediación, intentando, en los casos en que se requiere su presencia, mantener un punto de neutralidad y ecuanimidad. En los últimos años se ha podido percibir la importancia que los intendentes locales le asignan a la presencia de la capilla y la imagen de SC, en cuanto lo integran como un aspecto muy importante de la identidad local y forma parte obligada de visitas de toda autoridad o personaje importante, sea nacional o extranjera, que se encuentre en Florida. Asimismo, también se han dado oportunidades de colaboración para el emprendimiento de obras mixtas entre la Intendencia Departamental y la comisión directiva de la capilla, tales como pavimentación de calles del barrio, entre otras, así como la integración de autoridades municipales en la comisión de fiestas de la capilla. Generándose desde la institucionalidad municipal un claro apoyo a la promoción de esta festividad; otorgándole, si cabe, un mayor carácter secular a la legitimidad de esta expresión de religiosidad popular.

\section{LA FESTIVIDAD DE SAN CONO}

Desde sus orígenes, la procesión de SC ha sido una fiesta muy popular: bailes, fuegos artificiales, desfiles, ferias gastronómicas, visitantes y turistas de todo el país, música, y todo al estilo de las bulliciosas romerías italianas. Nada de lo que, al menos en sus orígenes, les agradase a las autoridades eclesiásticas: especialmente por el carácter profano de la celebración y la asociación entre un santo católico y todo tipo de juegos de azar, imágenes para su comercialización y demás asuntos mundanos. Tal y como señalan Sánchez Blanco et al. (1996), el año 1946 fue un año clave en el conflicto planteado. La Iglesia promulgaba que, «... la religión no es ese desfile de SC, ufano y rebelde, orgulloso y soberbio, sino la obediencia a la doctrina.... ${ }^{5}$. A su vez, el año siguiente, el periódico nacional El Heraldo afirmaba:

Resulta ahora que, sin curas, las procesiones tienen más éxito cada vez [...] la gente se hizo el gusto aún frente a la oposición del clero. Parece que, cuanto mayor es esa oposición, mayor éxito obtiene la Capilla, que puede decirse, constituye un nuevo culto independiente de la Iglesia ${ }^{6}$.

Es que SC se había convertido en asunto de debate nacional, siendo el santo preferido de los jugadores de juegos de azar, tales como quinielas, loterías e hipódromos. Llegando a estar prohibido por parte del Estado (que tiene el monopolio de los juegos de apuestas y de azar) el que las personas puedan apostar al número 3 en la quiniela nacional, por ser «el número del Santo» y frecuentemente número ganador.

Podemos considerar la procesión de SC como una de las expresiones más claras de la religiosidad popular de los uruguayos. Entendiendo por «religiosidad popular»:

\footnotetext{
5 Periódico Piedra Alta, 6/6/46, p. 2. Sánchez Blanco, A. y Geymonat, R., 1996.

${ }^{6}$ Periódico El Heraldo, 4/6/47, p. 2. Sánchez Blanco, A. y Geymonat, R., 1996.
} 
... un tipo de experiencia religiosa que se caracteriza por la incesante búsqueda de milagros que están relacionados con los problemas de la vida corriente... Lo realmente importante en la religiosidad popular, es la práctica, la acción; y respecto de ella, cuidar la forma exacta e inexcusable en que se deben llevar a cabo las ceremonias tendientes a la obtención de favores concretos (Renzo Pi Ugarte, 1998: 13).

De acuerdo a la investigación desarrollada por Coraza de los Santos (2006) esta manifestación de religiosidad popular concentra a una importante cantidad de personas, llegando a las 30000 personas en el año $2019^{7}$ y más de 200 puestos de venta de objetos diversos en la feria que se instala en las calles aledañas a la capilla. En el trabajo de campo desarrollado entre los años 1989 y 1996 se pudieron observar las características fundamentales que revestí a la fiesta en ese momento, llegando a desarrollar una tipología de quienes concurrían, sobre todo, a la fiesta del 3 de junio año a año. La observación participante permitió diferenciar las motivaciones que las personas tenían a la hora de concurrir a la procesión a partir de un instrumento de encuesta aplicado en la capilla y en las calles de la localidad de Florida. El resultado es el cuadro que a continuación se presenta (tabla 2).

\begin{tabular}{|c|c|c|c|}
\hline \multicolumn{4}{|c|}{$\begin{array}{l}\text { TABLA 2. TIPOS DE PARTICIPANTES, DEVOTOS, PROMESANTES } \\
\text { Y OFRENDAS EN LA PROCESION DE SAN CONO }\end{array}$} \\
\hline Participantes & $\begin{array}{l}\text { TIPOS DE } \\
\text { DEVOTOS }\end{array}$ & $\begin{array}{c}\text { TIPOS DE } \\
\text { PROMESANTES }\end{array}$ & OfRENDAS \\
\hline $\begin{array}{l}\text { - devotos } \\
\text { - por interés } \\
\text { comercial } \\
\text { - por interés } \\
\text { turístico }\end{array}$ & $\begin{array}{l}\text { - devotos en } \\
\text { general } \\
\text { - promesantes }\end{array}$ & $\begin{array}{l}\text { - con soporte material } \\
\text { (ofrenda) } \\
\text { - comportamientos que } \\
\text { en general implican } \\
\text { sacrificio } \\
\text { - concurrir a la fiesta } \\
\text { - participar de la procesión } \\
\text { - portar el hábito } \\
\text { - asumir sacrificios } \\
\text { corporales }\end{array}$ & $\begin{array}{l}\text { A) según motivación: } \\
\text { - por pedido } \\
\text { - por agradecimiento ("pago de } \\
\text { promesa") } \\
\text { B) según manifestación material: } \\
\text { - soportes de comunicación verbal } \\
\text { - esquelas } \\
\text { - placas } \\
\text { - fotografías } \\
\text { - objetos que implican valor monetario } \\
\text { - vestimentas } \\
\text { - objetos que representan triunfos } \\
\quad \text { deportivos } \\
\text { - hábitos } \\
\text { - objetos de uso cotidiano y/o } \\
\quad \text { decorativo } \\
\text { - exvotos en sentido estricto } \\
\text { - objetos relacionados con accidente y/o } \\
\quad \text { enfermedades }\end{array}$ \\
\hline
\end{tabular}

Fuente: Coraza de los Santos, E. (2006).

7 Si tenemos en cuenta que la población de Uruguay apenas supera los 3 millones de habitantes, es una cifra significativa. Recuperado de http://elheraldo.com.uy/04/06/2019/florida-volvio-convertirse-en-el-epicentro-religioso-del-pais/. Última consulta: 2/1/2021. 
El objetivo de esta tipología no era cuantificar sino justamente encontrar cuáles eran las razones que las personas tenían y esgrimían la hora de realizar las preguntas ¿por qué viene a la Fiesta de SC? ¿'Se considera devoto? ¿Viene por alguna promesa y trae alguna ofrenda? ¿Qué ofrenda trae y por qué motivo la trae? Esto se realizó durante todos los años que se desarrolló la investigación (1995-1997), lo que permitió comparar y se complementó con la observación en la sala de ofrendas. De esta forma, se puede observar la multicausalidad para justificar la visita, así como la diversidad de manifestaciones de las personas que van desde la simple observación, interés general, o comercial y/o turístico hasta quienes se identifican como «fieles» y desarrollan comportamientos y portan elementos que guardan una relación directa con el culto.

Por otra parte, $y$ tomando como referencia los trabajos de campo realizados más recientemente los días 1, 2 y 3 de junio de 2017 y 2019, también a través de la metodología cualitativa de observación participante y registros etnográficos, recabamos testimonios de peregrinos, así como del público en general asistente a la feria y fiesta durante los tres días de la celebración. Realizando relevamientos sobre la dinámica de la festividad, así como diversos elementos contextuales y situacionales.

Esta fiesta continúa siendo el evento más multitudinario del departamento de Florida, generando un gran dinamismo en la ciudad (comercial, gastronómico y de ocupación hotelera): el público asistente se compone de peregrinos locales, visitantes del resto del país (turistas y excursionistas) y del extranjero. Cabe destacar que este fenómeno nuclea a miles de visitantes cada ańo, siendo una de las festividades religiosas de mayor relevancia del Uruguay en cuanto a convocatoria de público: con casi 10000 asistentes el día de la procesión, 30000 asistentes durante los tres días de la festividad, declarados festivos oficiales en el departamento ${ }^{8}$. Generando, en consecuencia, un gran impacto a nivel turístico al punto de que constituye la principal fuente de ingresos por concepto de turismo del departamento y, en tal sentido, desde el gobierno departamental se promueve y fomenta el turismo religioso, así como otros atractivos de interés para el público que visita Florida con motivo de esta festividad. Lo que se persigue, desde lo municipal, es que los visitantes acudan también a otros destinos: visitas a estancias turísticas, establecimientos agrícolas, rurales y de producción lechera, rutas de senderismo y de la ruta jesuítica, deportes acuáticos en el río Santa Lucía, y campings, entre otras actividades y atractivos. Se ha podido observar a funcionarios de la Oficina de Turismo de la Intendencia Departamental de Florida repartiendo diversos folletos de promoción turística de atractivos del departamento. Además de ofrecer paseos con guías de turismo oficiales.

${ }^{8}$ Fuente: Oficina de la División de Turismo de la Ciudad de Florida para el año 2019. Es sabido que, durante el año 2020, y debido a la situación de pandemia, las actividades religiosas y profanas fueron suspendidas y se implementaron protocolos especiales. Recuperado de https://www. actualidad.com.uy/index.php/nacionales/3036-el-3-de-junio-no-habra-procesion-de-san-cono-enflorida-por-el-covid-19. Última consulta: 14/1/2021. 
Durante los días de los trabajos de campo se evidenció una gran cantidad de excursiones desplazadas desde lejanos puntos del país, en ómnibus o minibuses contratados, así como de visitantes que se desplazaron por sus propios medios, lo que se concluía por la gran cantidad de vehículos con matrículas de fuera del departamento de Florida y que saturaron la capacidad de estacionamiento de la localidad a lo largo de varias manzanas con más de 3 calles abarrotadas a cada lado de la avenida principal en torno a la capilla de SC por donde se desplaza la procesión. Al preguntar en la recepción de dos hoteles de la ciudad se pudo constatar que en esas fechas la ocupación hotelera es total, siendo gran parte de los visitantes excursionistas? : la afluencia de público excede enormemente la capacidad de los pocos establecimientos hoteleros de la ciudad (tabla 3).

\begin{tabular}{ll}
\hline \multicolumn{2}{c}{ TABLA 3. PRINCIPALES DATOS DE VISITANTES } \\
\hline & -30000 visitantes (similar númeto poblacional que tiene la ciudad). \\
& - Más de 100 óminbus de excursiones trasladan a casi 4000 personas. \\
& -500 personas arriban en tren provenientes de Montevideo y ad- \\
& yacencias. \\
Durante los tres días de la festividad & Más de 300 frecuencias de ómnibus de líneas regulares. \\
de San Cono la Oficina de Turismo & - Más de 1500 automóviles ingresan a la ciudad. \\
de la Intendencia Departamental & -500 personas solicitan información en el Centro de Información \\
de Florida estima regularmente y & Turística ubicado frente a la capilla. \\
de media los siguiente datos: & -3000 asistentes a las 8 carreras hípicas en el Hipódromo Parque \\
& Irineo Leguisamo. \\
& -1 raid hípico de 8 kilómetros de extensión. \\
\hline
\end{tabular}

Fuente: Intendencia Departamental de Florida (2021).

Agradecimientos por la información a la directora Lic. Carmen Passarella y al técnico Prof. Santiago Otaro, de la Oficina de Turismo de la Intendencia Departamental de Florida (2021).

Durante tres días (antes, durante y después del día de la festividad el 3 de junio) se instala una feria comercial. La misma ocupa la calle José Enrique Rodó y tiene una extensión de más de diez calles de largo. Avanzando por la misma, nos encontramos con puestos de los más diversos productos: ropa, artículos de electrónica (procedencia en general de China o Paraguay), souvenirs de SC, bijouterie, relojes, productos de belleza, de tocador y de ambiente, artesanías, piedras, artículos y utensilios de cocina, gastronomía, música, así como espectáculos, venta de juguetes, un parque de diversiones con juegos para nińos con varias plazas de comida, baños químicos y hasta exhibiciones exóticas de serpientes generando una elevada

9 Según la Organización Mundial del Turismo-OMT (2021) los visitantes se agrupan en las siguentes categorías: «turistas» son aquellos quienes pernoctan fuera de su municipio de residencia, $\mathrm{y}$ «excursionistas» son aquellos quienes no pernoctan fuera de su municipio de residencia, permaneciendo menos de 24 horas en el destino. Recuperado de https://www.unwto.org/es/glosario-terminos-turisticos. Última consulta: 14/1/2021. 


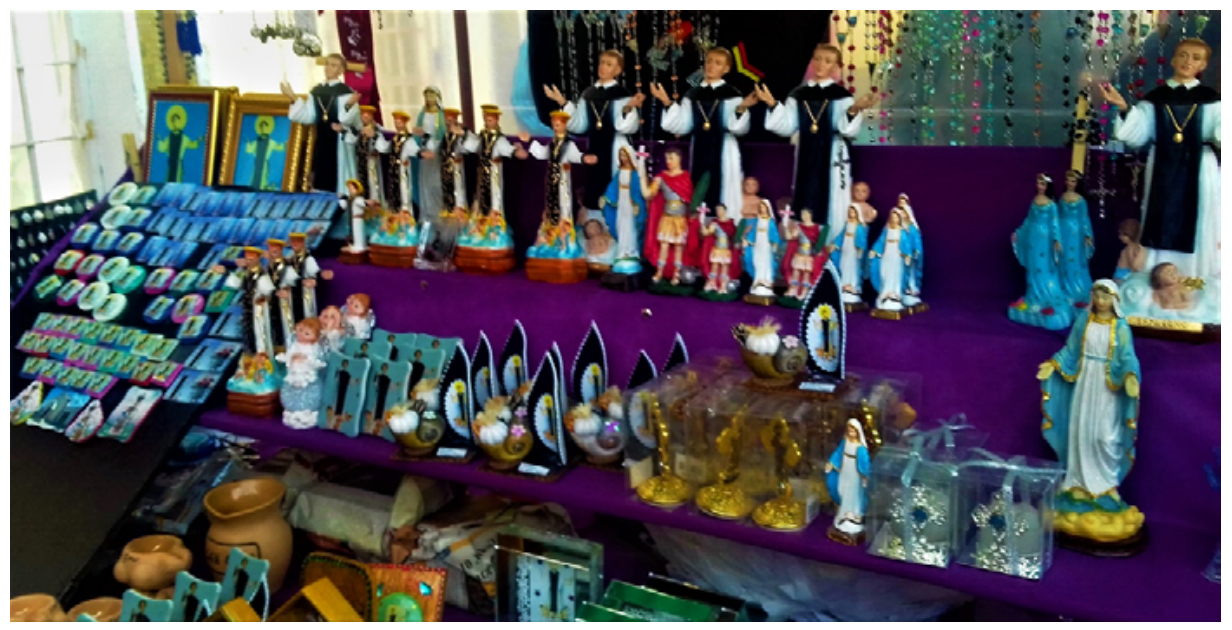

Imagen 2: imágenes de san Cono a la venta como souvenirs en puestos callejeros.

Fuente: fotografía De la Rosa, P. (2019).

concurrencia de público (imagen 2). Entre los souvenirs que están a la venta en los puestos alrededor de la capilla, destacan las imágenes, las velas, las estampitas y las medallas de SC que compiten con las que se venden en la propia capilla del santo a cargo de la comisión administradora.

La feria está sumamente concurrida, ocupando la totalidad de la calzada con puestos en ambas aceras. La distribución de los puestos es aleatoria en cuanto a los productos que se venden. Estas instalaciones imprimen un dinamismo económico y de afluencia de visitantes nunca visto el resto del año en la ciudad de Florida, y constituyen un paseo con muchos atractivos. La instalación de los puestos de esta feria callejera (especialmente los de venta de bebidas y alimentos) recibe el rechazo de gran parte de los comerciantes del lugar, quienes les atribuyen una gran competencia, la cual consideran desleal.

En cuanto al público observado, y ocasionalmente entrevistado, percibimos una gran diversidad en cuanto a edades, niveles socioeconómicos, procedencia de medios urbanos o rurales, público creyente o público pagano, lo cual da cuenta del factor aglutinador como elemento derivado de la festividad que imprime la religiosidad popular, que se da en un contexto de masividad del público. En palabras de uno de los entrevistados:

La feria de SC lo que tiene de característica es que trae mucha gente y hay distintas cosas, venden de todo. No es solamente un acto religioso como muchos creen, atrae de todo, y viene gente de muchos lados del Uruguay (hombre joven, residente local, 2/6/2019).

De los feriantes entrevistados (en su gran mayoría no residentes en la localidad), algunos manifiestan ser devotos del santo, y otros, simplemente asisten por 
su actividad económica. Este atractivo es asimilable con lo que relatan Sánchez y Geymonat (1996) en el sentido de que en sus orígenes tenía mayor similitud con la típica fiesta italiana sureña, en particular por su alegría, la que nunca se vio aplacada por los conflictos que hubo en su momento con la Iglesia católica, sino más bien todo lo contrario. Otro elemento característico que data de antańo, según los citados autores, y que observamos, es el ruido, ensordecedores anuncios y publicidad comercial y política, cierto clima caótico de multitudes que asisten a la capilla donde se encuentra la imagen de SC. Podemos rescatar elementos de sincretismo entre tradiciones criollas y gauchescas ${ }^{10}$, y las de origen italiano. Hoy día existe un gran involucramiento de distintas instituciones situadas en las inmediaciones de la feria (tales como clubes, asociaciones, sindicatos de trabajadores o escuelas).

Luego de la procesión, la noche finaliza al costado de la capilla con fuegos artificiales y bailes folclóricos con asistentes locales vestidos con trajes gauchescos. Finalizado el espectáculo pirotécnico, muchos jóvenes suelen «sanconear»" ${ }^{11}$ lo cual no implica entrar al templo ni realizar ninguna actividad religiosa sino, como nos comentó un grupo de jóvenes ataviados de gauchos (con facón ${ }^{12}$ a la cintura), que estaban dando una vuelta a ver si podían "conocer a alguien", entendiendo esto como una forma de flirtear.

Si bien aún resta el tercer día festivo, al finalizar los fuegos artificiales, la gran mayoría de los visitantes y excursionistas regresan a sus lugares de origen alrededor de las 19 horas en tren y en ómnibus de excursión y de línea. El tercer y último día asistimos a una de las misas de la catedral de Florida: altar mayor de la Iglesia católica en el departamento. Sorprendentemente, se nos confirma que la multitudinaria fiesta de SC no repercute en un aumento de los feligreses asistentes a las misas que se celebran durante esos días en la catedral, reafirmando el carácter de festividad tradicional y popular de SC. Cabe destacar que es en este recinto donde se ubica la «Virgen de los Treinta y Tres» (Patrona del Uruguay) y a quien está dedicada la catedral.

\section{LA PROCESIÓN, LA CAPILLA Y EL MUSEO}

Si nos acercamos al epicentro de toda esta festividad, la capilla de SC en los días que esta se realiza tradicionalmente (en torno al 3 de junio) se puede observar un cordón militar alrededor de misma y del Museo de SC contiguo donde, además, hay guardia de seguridad privada. Entre la presencia de autoridades civiles que están presentes los días de la fiesta, y sobre todo en la procesión de la imagen por las calles de la localidad, destacan el intendente y el secretario de Turismo del departamento

${ }^{10}$ Referido al gaucho. Mestizo que, en los siglos XVIII y xIX, habitaba la Argentina, Uruguay y Río Grande del Sur, en el Brasil, era jinete trashumante y diestro en los trabajos ganaderos (fuente: RAE, 2021).

${ }_{11}$ Práctica que define el paseo por los alrededores de la capilla de SC.

12 Cuchillo grande, recto y puntiagudo (fuente: RAE, 2021). Instrumento muy utilizado en las tareas del campo y que solía llevarse atravesado en la cintura. 
de Florida, además de autoridades militares, eclesiásticas como el obispo emérito de Florida y el actual obispo. No observamos presencia de otros eclesiásticos (sacerdotes), salvo los postulantes de la Orden de los Carmelitas Descalzos, que tienen cercano a la ciudad su centro de formación. Coloquialmente, uno de los pocos sacerdotes asistentes nos dijo que se trataba de un culto cuasiidolátrico, lo que motiva cierto rechazo por parte de los sacerdotes a participar.

La procesión se inicia con el toque de campanas y liberación de palomas además de pirotecnia, recorriendo durante unas horas el centro de la ciudad. Observamos personas de todas las edades, aunque mayormente de más de 50 años. Vemos manos levantadas, una multitud apretujada y compacta que se mueve lentamente, por las calles de la ciudad. Al iniciar la procesión, la imagen de SC es portada en hombros por feligreses muy formalmente vestidos, con traje. Los feligreses se acercan, besan las vestiduras, otros se arrodillan. También hay otro grupo de personas que se dirigen a la capilla, muchos vistiendo ropas símiles al santo (hábito religioso), y en procesión de penitencia de rodillas. En la plaza principal hay instalaciones de audio que replican a todo volumen el audio de la procesión retransmitido en directo por una emisora local de radio, que es sintonizada por los altavoces que se encuentran en la plaza. A su vez, delante de la cabecera de la procesión también se sitúa otro potente altavoz.

Otros asistentes visitan el Museo contiguo, en el cual se pueden apreciar diversos objetos: motocicletas, bicicletas, camisetas de jugadores de fútbol famosos. Llaman la atención los juguetes que se encuentran en el rincón izquierdo, entrando desde la capilla, según nos dicen, son de niños cuyos padres piden por sus vidas, y lograron una gracia (o milagro). Otros elementos significativos en vitrinas bajo llave y custodiadas son todo tipo valiosas joyas de oro y plata, relojes, copias de diplomas y monedas antiguas. También vemos cajas fuertes empotradas en las paredes. Las bicicletas y motocicletas se registran con los nombres de los oferentes y cada tanto se donan o ematan, pues es muy costoso mantenerlos a resguardo. De todas formas, hay una fuerte tradición en mantener las ofrendas en el Museo, ya que cada una de ellas representaría una promesa cumplida. Durante la procesión, el Museo es el lugar más custodiado por el ejército, la policía y la guardia privada. Las manifestaciones de devoción son de enorme entidad, en algunos casos verificándose ofrendas de importantes sumas de dinero, el total de lo que se recibe por ofrendas es enorme, debiendo vaciarse las alcancías varias veces al día al llenarse frecuentemente. Otro detalle importante es que también se encuentra en el Museo una imagen de SC que fue llevada allí hace décadas, cuando hubo un conflicto entre la comisión administradora y las autoridades eclesiásticas por la administración de la capilla. Se registró un importante operativo de seguridad durante el desarrollo de la festividad tanto en el tránsito como en lo policial.

Del público aleatoriamente entrevistado, una pequeña parte lo constituían residentes de la ciudad de Florida, mientras que la restante mayoría provenía de diversos departamentos del interior del Uruguay, o bien de la capital Montevideo. La afluencia de público es motivo de las palabras de clausura de la procesión por parte del obispo, quien agradece a todos los floridenses y a todos los que asistieron de otras partes de Uruguay, mencionando otros dos atractivos turísticos de la ciudad, la «Virgen de los Treinta y Tres» (Virgen Patrona del Uruguay) y la «Piedra Alta» en referencia a dos hitos históricos de la independencia del país: 
Esta hermosa ciudad que se distingue especialmente por este gran Santo que después de tanta procesión por las calles vuelve a su casa. También se distingue porque tenemos una imagen de la Virgen de los Treinta y Tres en nuestra Iglesia Catedral, allí juntito está la Patrona de la independencia nacional: tenemos esta patria libre, independiente, soberana y democrática.

\section{CONCLUSIONES}

Pensar en la Fiesta de San Cono en la ciudad de Florida y transformarla en un objeto-sujeto de estudio es hacerlo desde la Historia Reciente (Flier, 2014), al mismo tiempo que desde los estudios sobre la memoria, tanto en su dimensión individual como colectiva (Halbwachs, 2004). Esto quiere decir que forma parte de múltiples dimensiones que incluyen las experiencias vitales de las personas en términos de lugar (Massey, 2012), tanto las que pertenecen a las diferentes generaciones de la colectividad migrante italiana como la sociedad local, como en términos de la sociedad no solo floridense, sino nacional en la medida en que se incorporó a la cultura tradicionalmente laica del Uruguay. En este sentido, la periodicidad anual de la fiesta rememora a la vez que permite mantener los elementos de apropiación por parte de turistas y excursionistas que concurren de todas partes del país y se asocian a ella en diferentes dimensiones (culturales, espirituales, religiosas, turísticas, económicas, políticas), lo que hace que forme parte de ese pasado que no pasa. Asimismo, también refuerza la importancia de la fiesta como un evento multidimensional con intereses comunes, no exentos de conflictos, que se han constituido en un referente para la localidad el país (Marujo, 2015: 41).

Desde sus inicios, esta festividad religiosa y su devoción ha generado un abanico de discusiones en los planos político, periodístico, cultural, lúdico. A su vez, este fenómeno evidencia cuestiones que exceden lo religioso en cuanto al fenómeno local y su impacto en muchos aspectos: comercio, turismo, dinamismo urbano, generando así una congregación de gente que no necesariamente asiste por una motivación religiosa o de devoción al santo. Por lo que es evidente el gran impacto a nivel económico y social en la localidad. Desde el punto de vista económico, significa un enorme flujo comercial desplegándose una feria que únicamente se da en la ciudad en esas fechas. Desde el punto de vista turístico, destaca la gran presencia de ómnibus de excursiones que llevan público de todas partes del país: ya sea desde la capital, departamentos aledaños, del este, del litoral, y hasta de las zonas alejadas del norte del país. Y frecuencias de trenes desde la capital Montevideo, únicamente para la gran afluencia de excursionistas ${ }^{13}$. La oferta de ocio en esos tres días

${ }_{13}$ Es de señalar que, como parte de las políticas neoliberales, no solo en Uruguay, sino en toda la región, el servicio de trenes de pasajeros fue suspendido en 1987, quedando durante varias décadas solamente el de cargas, algo que ha sucedido prácticamente en toda América Latina. Por eso el hecho de que se pongan servicios ferroviarios para ese día le dota de excepcionalidad. 
es enorme y la necesaria como para satisfacer las demandas de los 30000 asistentes que se calcula acuden a las fiestas anualmente.

Resulta de interés el estudio de fenómenos de religiosidad popular en cuanto a los acontecimientos de la celebración de San Cono, en la conducta de pobladores locales, afluencia de visitantes (turistas y excursionistas) e inclusive en cuanto al rol de organismos del Estado y autoridades públicas en su involucramiento, especialmente en un contexto nacional de laicidad que se remonta a inicios del siglo xx. El fenómeno de la masividad que se evidencia da cuenta de una conmemoración que se inicia a partir de un hecho religioso, pero que tiene un efecto de congregación que va mucho más allá de lo religioso que incluye ritos "paganos» tales como la popularmente conocida "timba» o juegos de apuestas, así como otras costumbres que se asocian a la festividad en su despliegue no religioso tales como la fiesta, los bailes, la oferta gastronómica y de ocio que hacen de esta festividad el mayor ejemplo de turismo religioso en el Uruguay. Lo que nos da margen para considerar que hoy día conviven una festividad religiosa con elementos mixtos de una fiesta pagana ya que hay una importante participación noperegrina ni religiosa practicante en las festividades de San Cono. Generándose un factor de religiosidad popular que se mezcla con elementos identitarios de una histórica colectividad italiana instalada en el Uruguay, operando como factor de integración y un gran atractivo como oferta de turismo religioso. Confluyendo como asistentes toda la gama y matices que se sitúan entre los extremos del «turista puro» y el "peregrino puro» (Cánoves, 2006), destacando la numerosa presencia de «turistas religiosos». Finalmente cabe señalar que el análisis «turístico» de esta festividad se ha sucedido en el marco del estudio del complejo fenómeno histórico y popular que es la Festividad de San Cono en sí misma. Complejidad de análisis transversal en la que confluyen dos universos que tienen sus propias lógicas independientes: «el turismo» y "la religión». Festividad religiosa la cual ha devenido con el transcurso del tiempo ser también un atractivo turístico más, el cual se suma a la oferta turística de Florida, consolidándose actualmente como la mayor expresión de turismo religioso del país. 


\section{REFERENCIAS}

Barber, R. (1993). Pilgrimages. London: The Boydell Press.

Barrán, J.P. (1982). Apogeo y crisis del Uruguay pastoril y caudillesco.1839-1875. Montevideo: Ediciones de la Banda Oriental.

Barrán, J.P. (1994). Historia de la sensibilidad en el Uruguay. T II. El disciplinamiento (1860-1920). Montevideo: Ediciones de la Banda Oriental. Facultad de Humanidades y Ciencias.

Barrán, J.P. y Benjamín, N. (1990). Batlle, los estancieros y el imperio británico. T I. El Uruguay del Novecientos. Montevideo: Ediciones de la Banda Oriental.

Bjerg, M. y Otero, H. (comps.) (1995). Inmigración y Redes Sociales en la Argentina Moderna. Tandil: Instituto de Estudios Histórico-Sociales-Centro de Estudios Migratorios Latinoamericanos.

Bonfil Batalla, G. (1987). Lo propio y lo ajeno. una aproximación al problema del control cultural, en Colombres, Adolfo (comp.) La Cultura Popular. México: Dirección General de Culturas Populares-Premia Editores: 79-86.

Caetano, G. (2006). «Laicismo y política en el Uruguay contemporáneo. Una mirada desde la historia», 121-159, en Laicidad en América Latina y Europa. Repensando lo religioso entre lo público y lo privado en el siglo XXI.

Cánoves, G. (2006). «Turismo religioso en Montserrat: montaña de fe, montaña de turismo». Cuadernos de Turismo, (18), 63-76.

Cohen Orantes, I. (1981). «El concepto de integración», en Revista de la CEPAL, n. ${ }^{\circ}$ 15: 149-159.

Collins-Kreiner, N. (2010). «Researching pilgrimage: Continuity and transformations». Annals of Tourism Research, 37(2): 440-456.

Coraza de los Santos, E. (2006). La fiesta de San Cono: religiosidad popular y espacios de poder en el Uruguay contemporáneo. ISBN 978-84-7993-100-1.

Corbo, T.S. (2011). «La Iglesia y el proceso de secularización en el Uruguay moderno (1859-1919)». Hispania sacra, 63(127): 283-303.

Da Costa, N. (2003). «Religión y sociedad en el Uruguay del siglo XXI», en Un estudio de la religiosidad en Montevideo. Montevideo. CLAEH-Centro UNESCO de Montevideo.

Davis, N. (1973). «The Rites of Violence: Religious Riot in Sixteenth Century France», en Past and Present 59: 51-91.

De la Torre, G., Pérez, L. y Cárdenas, R. (2016). «Factores que determinan el crecimiento del turismo en destinos religiosos». Revista de Ciencias Sociales (Ve), 22(1): 85-97.

Digance, J. (2003). «Pilgrimage at contested sites». Annals of Tourism Research, 301: 143-159.

Doreen, M. (2012). Un sentido global del lugar. Barcelona, Icaria Editorial.

EL HERALDO (2019). Periódico. Recuperado de http://elheraldo.com.uy/04/06/2019/florida-volvio-convertirse-en-el-epicentro-religioso-del-pais/. Última consulta: 2/1/2021.

FLIER, P. (comp.) (2014). Dilemas, apuestas y reflexiones teórico metodológicas para los abordajes en Historia Reciente, Facultad de Humanidades y Ciencias de la Educación Universidad Nacional de La Plata, La Plata.

Foucault, M. (1979). Genealogía del Poder. Madrid: La Piqueta.

Foucault, M. (1981). Un diálogo sobre el poder. Madrid: Alianza, España. 
Griffiths, M. (2011). «Those who come to pray and those who come to look: interactions between visitors and congregations». Journal of Heritage Tourism, 6(1): 63-72.

Halbwachs, M. (2004). La memoria colectiva. Zaragoza: Prensas Universitarias de Zaragoza.

Marujo, N. (2015). «Eventos culturales y motivaciones de los turistas. La Fiesta de Fin de Año en Isla de Madeira-Portugal», en Estudios y Perspectivas en Turismo, vol. 24, núm. 1, 40-55.

Nyaupane, G., Timothy, D.J. y Poudel, S. (2015). «Understanding tourists in religious destinations: A social distance perspective». Tourism Management, 48: 343-353.

OMT (2021). Organización Mundial del Turismo. Recuperado de https://www.unwto.org/es/glosario-terminos-turisticos. Última consulta: 10/2/2021.

Pi-Hugarte, R. (1998). Los cultos de posesión en Uruguay. Montevideo: Ediciones Banda Oriental.

Real Academia Española (RAE) Recuperado de https://dle.rae.es/. Última consulta: 10/2/2021.

Sánchez Blanco, A. y Geymonat, R. (1996). La búsqueda de lo maravilloso SC y otras devociones populares.

SHACKLEY, M. (2001). Managing sacred sites: Service provision and visitor experience. London: Thomson.

Sмiтh, V. (1992). «Introduction: the quest in guest». Annals of Tourism Research, 19: 1-17.

Terzidou, M., Scarles, C. y Saunders, M. (2018). «The complexities of religious tourism motivations: Sacred places, vows and visions». Annals of Tourism Research, 70: 54-65.

Thompson, E. (1981). Miseria de la teoría. Barcelona: Crítica.

Torres, F. (2011). La inserción de los migrantes. Luces y sombras de un proceso. Madrid: Talasa Ediciones.

Torres, V., Barquín, R. y García, M. (2017). «El vínculo turismo-procesión: Un acercamiento desde la producción científica en inglés y en español». Estudios y Perspectivas en Turismo, 26(1): 86-106.

UNESCO (2003). Convención para la Salvaguardia del Patrimonio Cultural Inmaterial. Recuperado de https://ich.unesco.org/es/convenci\%C3\%B3n\#art2. Última consulta: 2/2/2021.

Valera, S. (1996). «Análisis de los aspectos simbólicos del espacio urbano. Perspectivas desde la Psicología Ambiental». Revista de Psicología Universitas Tarraconensis, 18(1): 63-84. 
